\title{
Practical modes of presentation
}

Ephraim Glick

University of St Andrews

\begin{abstract}
The Intellectualist thesis that know-how is a kind of propositional knowledge faces a simple problem: For any proposition $p$, it seems that one could know $p$ without knowing how to do the activity in question. For example, it seems that one could know that $w$ is a way to swim even if one didn't know how to swim oneself. In this paper I argue that this "sufficiency problem" cannot be adequately addressed by appealing to practical modes of presentation.
\end{abstract}

\section{The basic objection to Intellectualism}

Suppose John knows how to swim. If Intellectualism is correct, John's know-how is knowledge of some proposition. Thus knowledge of a certain proposition (perhaps a proposition of a sort determined by a given context) ought to be both necessary and sufficient for John to know how to swim. Here I will focus on sufficiency. For some proposition p:

(1) Necessarily, if John knows $p$ then John knows how to swim.

What sort of proposition might $\mathrm{p}$ be? One simple proposal would be that it's a proposition of the following sort: that one can swim by doing such-and-such. But what might "such-and-such" be? Well, some ways one could swim include: By doing the backstroke. By doing the crawl. By repeatedly kicking one's legs in a scissor-like motion while dragging one arms downward and back through the water so as to propel one's body in the opposite direction. However, John might not know how to swim despite knowing that one can swim by doing those things. So it would seem that either (a) Intellectualism is false, or (b) we haven't picked the right sort of proposition for the Intellectualist to use in completing (1).

Unfortunately, no one has supported (b) by improving substantially on the inadequate candidates for $\mathrm{p}$ noted above. And if no one can point to a fact knowledge of which is plausibly sufficient for knowing how swim, this is a prima facie reason to be skeptical about Intellectualism. 
Call this the sufficiency problem for Intellectualism. In their influential defence of the view, Stanley and Williamson (2001: 428) admit that a preliminary version of their account faces such a problem. Their proposal tells us that necessarily, if John knows that $w$ is a way for him to swim (for some contextually relevant way w), then John knows how to swim. They raise the problem by saying that John might not know how to swim despite being in a position to demonstrate someone's way of swimming and knowledgeably declare "that is a way for me to swim".

Stanley and Williamson's response to the problem, later adapted by Stanley (2011), is to claim that know-how requires the subject to possess the relevant propositional knowledge under a practical mode of presentation (PMP). The remainder of my discussion will be devoted to explaining what this suggestion amounts to and showing that it does not solve the sufficiency problem for Intellectualism.

I'll begin by discussing two extant objections to PMPs. These are, first, that the postulation of PMPs is not sufficiently motivated, and second, that appealing to PMPs covertly reintroduces something anti-Intellectualist in the account of know-how. I argue that these objections are largely unsuccessful, but that there is still a serious question as to whether the Intellectualist has an account of PMPs that is sufficiently clear and substantial to provide an account of know-how. After looking more closely at the account of PMPs due to Stanley and Stanley and Williamson, I argue for a negative answer to this question.

A note before beginning: There is a second main tenet of Intellectualism I have not yet mentioned - that know-how does not require ability. See, for instance, (Ginet 1975) and (Stanley and Williamson 2001). While this tenet could be given up without giving up the claim that knowhow is a kind of knowledge-that, ${ }^{1}$ I will focus on a form of Intellectualism that retains both claims. ${ }^{2}$ I will thus assume that it would be giving up Intellectualism to respond to the sufficiency problem by saying, e.g., that what $\mathrm{S}$ knows in knowing how to swim is the proposition that $\mathrm{S}$ is able to swim F-ly. Similarly, if one must be able to swim in order to think of a way of swimming as "this way" of swimming, then Intellectualists cannot say that knowing how to swim is knowing what one would express by saying "this is a way for me to swim."

\footnotetext{
${ }^{1}$ I discuss this possibility a bit more below.

${ }^{2}$ I will thus not consider the view of Bengson and Moffett (2012b), who consider themselves Intellectualists but give up the claim that know-how is a kind of knowledge-that.
} 


\section{The motivation for practical modes of presentation}

Why believe there is any such thing as a practical mode of presentation? Stanley and Williamson (2001: 429) say that one can give an "existence proof" for PMPs. The idea is that the argument for standard modes of presentation is sound, and one can give an analogous argument for PMPs, so there is a sound argument for PMPs. In the standard case, one infers that propositions can be entertained under different modes of presentation from the fact that, e.g., the complement clauses of (2a) and (2b) express the same proposition despite the belief attributions possibly differing in intuitive truth-value.
a. John believes that that man has burning pants.
b. John believes that he himself has burning pants.

It is not clear exactly how we are to imagine the argument proceeding, but perhaps we can put it this way: If the contents of the that-clauses in $(2 \mathrm{a})$ and $(2 \mathrm{~b})$ are the same proposition, then it can't be that John believes one and doesn't believe the other. Thus our intuition that (2a) and (2b) sometimes differ in truth-value shows that our judgments about attitude attributions are sensitive to more than just which propositions individuals believe. The extra element is the mode of presentation under which the individuals believe those propositions.

At a first pass, a parallel argument for PMPs would appeal to the claim that the complement clauses of (3a) and (3b) express the same proposition. (In interpreting (3a), imagine a context in which someone is riding a bicycle in a way which is a way in which Hannah could ride, and the speaker is attempting to demonstrate that way.)
a. Hannah knows that that way is a way for her to ride a bicycle.
b. Hannah knows how to ride a bicycle.

However, we must take the argument for PMPs to have a slightly different form, since according to standard views (including Stanley and Williamson's) the content of (3b)'s complement isn't a proposition at all, but rather the meaning of an embedded question. The upshot of this, they argue, is that (3b) is true iff for some contextually relevant way $w$ of riding a bicycle, Hannah knows that $w$ is a way for her to ride a bicycle. If they're right, then in contrast with (3a), (3b) 
expresses a quantified claim and doesn't specify a particular proposition known by Hannah.

Let us suppose that in an appropriate context for the use of (3a), the demonstrated way $w$ of cycling will count as contextually relevant. Then Hannah's knowing that $w$ is a way for her to cycle should, on Stanley and Williamson's theory, suffice for the truth of (3b). To get as close as we can to an analogy with the argument from (2a) and (2b) for standard modes of presentation, we can try putting the argument for PMPs as follows.

The content of the that-clause in (3a) is a certain proposition $p$ of a sort such that $(3 \mathrm{~b})$ says that Hannah knows a proposition of that sort. And thus it's impossible for Hannah to know p while not knowing a proposition of the relevant sort. But then our intuition that (3a) might be true while (3b) were false shows that our judgments about know-how attributions are sensitive to more than just which sorts of propositions individuals believe. The extra element is the mode of presentation under which individuals believe propositions of those sorts.

Alva Noë (2005: 288) has objected to the alleged existence proof for PMPs. While he poses his objection to the first-pass argument I have just been correcting, the objection carries over to the corrected version. His point is that the existence proof takes it as a premise that ( $3 \mathrm{~b})$ attributes to Hannah knowledge of a proposition like the one expressed by the complement in (3a). And that premise is hardly neutral ground between the Intellectualist and Anti-Intellectualist. For the fact that it is easy to imagine cases in which (3a) seems true while ( $3 b$ ) seems false is an objection to the premise - it is simply an illustration of the sufficiency problem for Intellectualism. Noë concludes that we have no existence proof for PMPs. Rather than postulate them in response to the sufficiency problem, we might equally conclude that Stanley and Williamson's premise is false.

The natural reply, anticipated by Noë, is that if the existence proof for PMPs fails, so does the existence proof for standard modes of presentation. Noë's rejoinder is that in the standard case, philosophers take there to be compelling reasons for identifying the propositional contents of the that-clauses in $(2 \mathrm{a})$ and $(2 \mathrm{~b})$, and it is this that motivates the hypothesis of modes of presentation. Noë claims that in contrast, "we have no independent reason to believe" the analogous claim about (3a) and (3b), so the argument in favour of PMPs lacks force.

I think sustaining this rejoinder is not at all simple. For Stanley and Williamson offer an extended argument in favour of their premise. They take standard theories in syntax and formal 
semantics to establish that (3b) attributes knowledge of a proposition like the one expressed by the complement in (3a). And if they are right, then surely this is the sort of independent reason Noë is looking for. It is worth noting, then, that Noë's criticism of the existence proof for PMPs cannot succeed unless Stanley and Williamson's linguistic argument fails.

As reconstructions of the argument elsewhere in the literature show, ${ }^{3}$ it is hard to see why the argument should fail. The central premises tell us what the linguistic components of a know-how attribution are and what their individual semantic interpretations are. Those interpretations are motivated entirely independently of the debate over know-how, but when they are composed together in 'S knows how to $\phi$, they generate the result that the latter sentence is true iff S knows a proposition of a certain sort. Any compelling reply to the argument must either dispute the linguistic premises or show how, contrary to appearance, the argument could be invalid.

Now, Noë does object to the linguistic argument, but does not make it clear what the problem is supposed to be. He neither challenges the premises from syntax and formal semantics, nor reconstructs the argument in a way that allows him to identify any invalid step. Without doing one of those things, Noë's criticism of the existence proof for PMPs is incomplete.

Even if Noë's objection were correct, his more general line of criticism against PMPs could be deflected. For the general criticism is that PMPs are not sufficiently motivated, and Stanley and Williamson could offer motivations other than the "existence proof". Stanley attempts to do this in more recent work (2011), though his theory there is put in Fregean terms. Rather than practical modes of presentation of Russellian propositions, know-how is analysed in terms of practical ways of thinking that are parts of propositions.

Stanley claims that "practical ways of thinking" are "widely recognized" as theoretically necessary. He cites Heidegger for support (2011: 124). I confess to finding Heidegger's thoughts opaque, and Stanley does not provide much in the way of helpful interpretation. He says that Heidegger "draws our attention to the fact that there is a practical way of thinking about a thing, one that is revealed paradigmatically in operating with a tool". Let's not worry about whether this is really Heidegger's view, and focus instead on the claim itself. Granted, when one learns to operate with a hammer, say, one comes to know how to use a hammer, and granted, when one operates with a hammer one may come to have some new thoughts about the hammer. E.g., one

${ }^{3}$ See (Glick 2011). 
becomes able to think of the hammer as the thing with which one is doing "this", or to think of the hammer as the thing one uses "thusly". But it would be nice to be told why the hammerwielder's thoughts about the hammer are so importantly different from the thoughts that an observer has when she thinks of the hammer as the thing with which he is doing that. The operator and the observer are differently positioned with respect to the hammer operations, and that allows them to think of the operations in slightly different ways. That is at least one difference between the thoughts the two can have. But it is hard to see why the operator's thoughts are supposed to be distinctively practical, rather than simply being demonstrative thoughts of a sort analogous to the observer's, but from a different perspective. ${ }^{4}$

One suggestion would be that the operator has proprioceptive access to his action, whereas the observer does not. However, a proprioceptively based way of thinking about an action cannot be required for know-how. For, first, there is know-how that does not involve bodily movement at all, and so does not involve any proprioception. One may know how to solve a certain puzzle, perform a certain calculation, and so on. The proprioception in the case of hammering must not be essential to the analysis of PMPs. Second, even for the case of actions that involve bodily movements, there can be know-how in the absence of proprioception. To claim otherwise would commit one to the implausible view that a proprioceptive disorder would not simply make it difficult for someone to learn to, say, knit, but could make it metaphysically impossible. Learning to perform bodily actions in the absence of proprioceptive feedback is not merely metaphysically possible, but actual (Azar 1998).

A related suggestion would be that the operator experiences what it is like to hammer in way $w$, and so thinks of $w$ by means of this experience. The idea here would resemble the view that there are phenomenal concepts, concepts that (very roughly) in normal conditions, someone can only come to possess by having a certain sort of experience. For the practical way of thinking of $w$ is supposed to be one that distinguishes the operator and the observer. Only someone who has experienced competently operated with a hammer can think of $w$ practically. An initial objection is simply that it would be unfortunate for an account of know-how to commit us to something like phenomenal concepts, as the existence of such concepts is controversial (see, e.g., Ball 2009). But more importantly, it does not seem that the suggestion would be adequate. It rules out the

${ }^{4}$ Thanks to an anonymous Noûs reviewer for pressing me to clarify the discussion below. 
possibility of knowing how to do an action that lacks an accompanying phenomenology. Even if we are unsure whether there are such actions, do we want to rule it metaphysically impossible? Furthermore, one can continue to know how to do something even if one is no longer able to think of his or her way $w$ of doing it as a way the performance of which has a certain phenomenology. For instance, suppose Joe learned to wiggle his ears, and so experienced what it is like to wiggle his ears. If many years have elapsed since he last wiggled his ears, he may have no recollection of what it was like to do so. He may now have no phenomenological mode of presentation of his way of ear-wiggling. This does not entail that he no longer knows how to wiggle his ears. He might simply need to wiggle them to remind himself of what it is like.

There remains the bare suggestion that the hammer-wielder's thought is "action-based" while the observer's is not. It is not clear what this amounts to. Of course, Intellectualists might respond that it is difficult to explain what any mode of presentation amounts to. They could then argue with the opponent of PMPs about whether or not we really have a better grip on, say, first-personal modes of presentation or demonstrative modes of presentation. I will set this aside for now (for more discussion, see the penultimate section of this paper as well as the section below about analogies between PMPs and other modes of presentation), as I think there is a further serious worry for the attempt to use Heidegger's sort of example to motivate PMPs.

Suppose we agree not only that the hammer-operator can think of his way of hammering in a way that the observer cannot, say as "this way of hammering", but also agree with the terminological stipulation that the hammer-operator's thoughts involve "practical ways of thinking". Where is the argument that such ways of thinking have the properties needed for the Intellectualist's account of know-how? Plausibly, the operator's thought that this way of hammering is $F$ is made possible by his coming to know how to use the hammer. Only after one knows how to operate with a tool can one operate with that tool and know that it is used "like this". More generally, it's in virtue of learning to do something, and so coming to know how to do it, that one ends up in a position to grasp that this way is $F$, or that this is the way to do such-and-such. What the defender of PMPs needs is the claim that know-how is in part constituted by such ways of thinking, so that it's because one grasps that this is the way to do such-and-such that one knows how to do it, rather than vice versa. But that claim is not entailed by the existence of "practical" ways of thinking if know-how is a prerequisite for thinking in those ways. To state the point again in a slightly different 
way: Perhaps the opponent of PMPs will grant that there are "action-based" thoughts that one is able to grasp iff one knows how to do a certain action. But the opponent might simply maintain that acquiring know-how results in the accessibility of those new thoughts, rather than vice versa. If there is an argument for the claim that the order of explanation goes the way the Intellectualist wants, I don't see it in the literature.

Now, in addition to using simple examples like Heidegger's to motivate the claim that there are PMPs, Stanley also uses cases of informative identities to argue that practical ways of thinking must be accepted by anyone who goes in for ways of thinking at all (2011: 123). He thinks that ordinary modes of presentation are motivated by cases like those in standard versions of Frege's Puzzle, and that one can easily construct similar puzzle cases where one of the "ways of thinking" involved is distinctively practical. Stanley seems to have in a mind a case like the following, which I elaborate based on Stanley's quotation from the work of Christopher Peacocke.

A pianist performs an intricate series of finger movements in the course of playing a difficult piece. The pianist thinks of the series of movements "in an action-based way" when she plays the piece, but has no idea that the series of movements is the series consisting of exactly such-andsuch fingers pressing on such-and-such keys at such-and-such times. When she later reads a description of exactly the movements she performed, she learns something new and surprising.

It does seem clear that one can fail to know that this series of movements is such-and-such series of movements. But as in the hammer case above, the datum does not establish what the defender of PMPs wants to establish. The main worries raised above apply here just as well. First, it is just not obvious what the distinctive "action-based way" in which the pianist can think of the movements is supposed to amount to. Granted, she can think of the movements as these movements. But practical ways of thinking are supposed to differ in some important way from the ways of thinking employed by external observers of a given action, ${ }^{5}$ and it is hard to see what the relevant difference is between the pianist's thought and the observer's thought about those movements. The pianist is performing the movements and the observer is not, so they are differently positioned with respect to the movements. But what is distinctively practical about the pianist's thought? As argued above, it must not be that she is thinking of her finger movements proprioceptively or by means of some phenomenology. We're left without an understanding of what is

\footnotetext{
${ }^{5}$ At least, observers who don't know how to perform the action.
} 
"action-based" about her thought.

The second and more important worry, as in the hammer case above, is that even if the pianist is having some distinctively practical thought, it is unclear what the relationship is between that thought and the pianist's know-how. Clearly one must be in a position to perform the series of movements in order to think of the movements as these movements, and one's being in such a position is explained by one's knowing how to perform the movements. And that is compatible with the know-how being a prerequisite for the sort of thought in question, as opposed to the know-how being partly constituted by the grasping of such a thought. It is the latter claim that Stanley needs for practical ways of thinking to explain the difference between know-how and ordinary knowledge-that, but he does not give an argument for it.

While the above arguments for positing PMPs (or Fregean practical ways of thinking) are somewhat lacking, it would be a mistake to infer that there is no reason to take PMPs seriously. For if the Intellectualist's complete theory manages to account for all the relevant facts about know-how in a plausible and sufficiently clear way, and does so by including PMPs, then perhaps there is no obligation to provide an independent motivation for the existence of PMPs. They could earn their place by contributing to the overall theory. The real question then is whether the overall theory accounts for all the facts in a plausible and sufficiently clear way. I will argue later that it does not, but first I want to consider another extant criticism of PMPs.

\section{Are PMPs covertly anti-Intellectualist?}

The Rylean has a pleasingly simple story to tell about the sufficiency problem for Intellectualism: knowing that $\mathrm{p}$ isn't sufficient for know-how because it isn't sufficient for ability, a necessary condition for know-how. Intellectualists jettison Ryle's necessary condition for know-how, are left with counterexamples to their view, and in response introduce a new necessary condition for know-how. Knowing that $\mathrm{p}$ isn't sufficient for know-how because it isn't sufficient for $\mathrm{X}$, and $\mathrm{X}$ is a necessary condition for know-how. The worry now is that this $\mathrm{X}-$ the knowledge that p's being possessed under a PMP - can only be explained in a way unfriendly to Intellectualism.

Koethe (2002: 326) writes, "What Stanley and Williamson's account of what it is for someone to know how to $\mathrm{F}$ really comes to, with its talk of entertaining a proposition under a practical mode of presentation, is [the following:]" 
(4) Someone knows how to F just in case he knows, of some way w, that w is a way for him to F, and he knows how to instantiate w himself (and thereby F).

Koethe offers a short argument for the claim that Stanley and Williamson's view amounts to (4): While Intellectualists think knowledge how to F can be possessed in the absence of an ability to F, even Stanley and Williamson think such cases only occur when there is a special obstacle of some kind preventing the agent from manifesting his knowledge how to F. Let us state this principle as follows:

$$
\text { Necessarily, if } \mathrm{S} \text { knows how to } \mathrm{F} \text { and } \mathrm{S} \text { faces no impediments to F-ing, then } \mathrm{S} \text { is able }
$$
to $\mathrm{F}$.

Now suppose S knows under a PMP that $w$ is a way for him to F, but S doesn't know how to instantiate $w$. If S doesn't know how to instantiate $w, S$ might therefore not be able to instantiate $w$, and hence not be able to F. And thus if Stanley and Williamson's analysis of know-how were correct, S might know how to F without being able to F "even though there is no impediment, handicap, or other barrier to his being able to F” Koethe (2002: 326). But this is impossible given (5). Thus it must be that if $\mathrm{S}$ knows under a PMP that $w$ is a way for him to $\mathrm{F}$, he knows how to instantiate $w$. And if S knows how to instantiate $w$, that seems sufficient to provide the "practical" element Stanley and Williamson want to add to the claim that S knows that $w$ is a way for him to F. So their view can just be taken as (4), where the notion of a PMP is spelled out.

Suppose the defenders of PMPs try to respond by accepting Koethe's point while maintaining that their view nevertheless counts as Intellectualist. They might say: "Perhaps (4) is true, so that (for instance) S knows how to swim iff S knows a certain fact about $w$ and knows how to instantiate $w$. But this still allows that know-how is a kind of knowledge-that! For the latter claim doesn't require a reduction." Stanley and Williamson (2001: 434) note that an assassination is a kind of killing even if no reductive analysis of assassination in terms of killing can be given. Perhaps all we can say is that the following is true: an assassination takes place iff it's true that a killing takes place and true that an assassination takes place.

I doubt that this defensive move would leave Intellectualists in an acceptable position. For if 
their view really amounts only to (4), their view does not yet entail the desired conclusion that know-how is a kind of knowledge-that. For note that the above non-reductive biconditional about assassination is consistent with assassinations merely being always accompanied by killings while not themselves being killings. Similarly, the analysis of know-how that Koethe takes Stanley and Williamson to be content with is consistent with know-how merely being always accompanied by some knowledge-that, but not being knowledge-that.

It may help to consider a better analogy. The following seems true: Necessarily, S regrets that $\mathrm{p}$ iff $\mathrm{S}$ believes that $\mathrm{p}$ and $\mathrm{S}$ regrets that $\mathrm{p}$. This allows that regret is a kind of belief, but also allows that regret is not a kind of belief. All it entails is that regret requires belief. So Stanley and Williamson could rest content with (4) if they merely wanted to claim that for each piece of knowhow there is a corresponding piece of propositional knowledge required. ${ }^{6}$ But that view would not suffice for the claim that know-how is a kind of knowledge-that, and it is this latter claim that the Intellectualist hopes to establish. ${ }^{7}$

A second way that the defender of PMPs could try to respond ${ }^{8}$ would be to give up (5), allowing that someone could know how to F and not be able to F despite lack of any impediment. As Koethe notes (326), this seems not to appeal to Stanley and Williamson. Discussing Frank Jackson's hypothetical color scientist raised in a black and white room, they write that it would be "absurd" to suppose that she knew how to imagine an experience of red despite being unable to do so. They ask rhetorically, "If she knows how to imagine an experience of red, why is she unable to imagine such an experience?" (2001: 443) It seems, then, that to reject (5) would be to diverge from the position that Koethe is targeting.

But nothing in the core of Stanley and Williamson's view commits them to the position they took regarding Mary. For all they say elsewhere in their theory about the connection between know-how and ability, it could be commonplace for someone to know how to do something while being unable to do it, despite the lack of any impediment. So they or other Intellectualists could well resist Koethe's argument that PMPs need explanation in terms of know-how by giving up (5).

One might worry that giving up (5) would make PMPs seem more mysterious and would

\footnotetext{
${ }^{6}$ Thus I agree in part with Jeremy Fantl (2008: 460).

${ }^{7}$ Should they hope to establish the stronger claim? I think so, for if the knowledge-that is merely required by, or a component of, the know-how, one could worry that the other components are the ones that explain everything interesting about know-how.

${ }^{8}$ Stanley does not explicitly discuss Koethe, so what follows is my own suggestion on his behalf.
} 
threaten the role of know-how in an explanation of action. What does knowledge that $\mathrm{p}$ under a PMP contribute to successful action that isn't already contributed by knowledge that $\mathrm{p}$ simpliciter? While the present response to Koethe may block his argument, it makes more pressing the worry that PMPs are not sufficiently clear to support much weight in an account of knowhow. So let us face this latter question directly, exploring the extent to which PMPs can be clearly explained.

\section{Characterizing practical modes of presentation}

Philosophers are familiar with the notion of a mode of presentation, but practical modes of presentation (PMPs) are an innovation. Critics of Stanley and Williamson have worried that it is simply unclear what PMPs could possibly be, and thus that a theory of know-how relying essentially on PMPs cannot be taken seriously. Schiffer (2002: 201), for instance, complains that "we are not given the slightest clue as to what "practical modes of presentation" are like". This isn't quite fair. We are given the slightest clue in the paper he is criticising, and given further clues in (Stanley 2011). In the former, we are told the following:

There is a conventional connection between pronouns such as 'he himself and firstperson modes of presentation. Similarly, there is a conventional connection between the use of constructions that embed instances of the schema 'how to F', and practical modes of presentations of ways. Such conventional connections between linguistic constructions and modes of presentation have obvious communicative value in both the case of first-person propositional attitude ascriptions and the constructions that concern us in this paper. Given such a connection, use of the relevant construction provides extra information about how the ascribee thinks about one of the propositional constituents, information that allows the hearer to predict how the ascribee will act in various situations. [...] Thinking of a person as oneself entails being disposed to behave in certain ways, or form certain beliefs, given relevant input from that person. Similarly, thinking of a place as here entails being disposed to behave in certain ways, or form certain beliefs, given relevant input from that place. Analogously, thinking of a way under a practical mode of presentation undoubtedly entails the possession of certain complex dispositions. It is for this reason that there are intricate connections between knowinghow and dispositional states.

Drawing an analogy between PMPs and indexical modes of presentation is an initially promising strategy for the Intellectualist, and it is not surprising that it is central to Stanley and Williamson's work. As they set it out, the analogy appeals to three main features of indexical modes of presentation. 
First, some modes of presentation are conventionally connected with certain distinctive linguistic constructions. The claim (6), for instance, would convey that John's thought involves a first-personal mode of presentation.

John thinks that he himself is on fire.

If John were confused about his identity, he might instead have a non-first-personal thought that a certain person was on fire, where that person turned out to be John. In that scenario it would seem wrong to describe John with (6), though (7) could still be intuitively true. ${ }^{9}$

(7) John thinks that that guy is on fire.

To discuss the fact that indexical modes of presentation are connected in this way to certain linguistic constructions like the one in (6), let us say that such modes have "conventional locutions".

Second, to have a thought involving an indexical mode of presentation involves thinking about something in a particular way. A difference between John's having a belief about himself under a first-personal mode of presentation and his having a non-first-personal belief is a difference in the way John thinks of himself. As Stanley and Williamson put it, when you have information about the mode of presentation under which someone has an attitude toward a Russellian proposition, you have information about "how the ascribee thinks about one of the propositional constituents." Perhaps modes of presentation are nothing but ways of thinking, but perhaps something additional is required. Let's leave this open and simply say that indexical modes of presentation involve distinctive ways of thinking of objects.

Third, when someone has a thought under an indexical mode of presentation, this entails that he or she possesses distinctive behavioral dispositions. The relevant sort of consideration is the following. When someone has a first-personal belief that he or she is on fire, then given a general desire to extinguish fires, that person will be disposed to drop and roll or to jump in nearby bodies of water. A non-first-personal belief would not, together with the same general needs or desires, typically produce that behavior. Stanley (2011: 109) says "To think of an object

\footnotetext{
${ }^{9}$ See (Perry 2000) for influential discussion of this and similar examples.
} 
in the world as myself is to possess certain dispositions involving that object in the world. If that object in the world is cold, I will clothe it; if it is wet I will dry it, etc." Let's describe this feature of indexical modes of presentation by saying that they entail distinctive dispositions.

Stanley and Williamson's complete explanation of PMPs, as far as I can see, consists of the claim that PMPs are analogous to indexical modes of presentation in that they possess the three features just described. The main addition of Stanley $(2011)^{10}$ is a general characterisation of Fregean ways of thinking. Stanley appeals to Gareth Evans' work, proposing that a given way of thinking can be defined in terms of the relation $\mathrm{R}$ between an individual and an object which is the relation in virtue of which the individual is thinking of the object. For instance, there's some relation $\mathrm{R}_{1}$ such that someone having a first-personal thought thinks of themselves first-personally in virtue of standing in $\mathrm{R}_{1}$ to themselves. "There obviously is such a relation, because there is something in virtue of which I think of the object that is in fact myself as myself" (99). However, Stanley is explicit that he does not take himself to be giving "an account of the nature of the $\mathrm{R}_{1}$ relation, i.e. an account of what it is to think of oneself as oneself" (88). Similarly, Stanley does not provide an account of what it is to employ a practical way of thinking about a way of doing something. The framework from Evans may help relieve worries about the ontology of modes of presentation (Stanley 99), ${ }^{11}$ but it does not provide an account of what it is to think of something in a given way. To provide the latter we would, Stanley emphasises, need to understand the distinctive dispositions involved in that way of thinking of something (110). This underscores the importance of dispositions in the account of PMPs and in the analogy between PMPs and other modes of presentation.

We can thus characterize the positive theory of practical modes of presentation as follows.

(8) PMPs are like indexical modes of presentation in that:
a. PMPs have conventional locutions.
b. PMPs involve distinctive ways of thinking.
c. PMPs entail distinctive dispositions.

\footnotetext{
${ }^{10}$ See also Stanley (2012: 775-77).

${ }^{11}$ Stalnaker (2012) worries that Evans' idea faces serious problems, and Stanley (2012) replies. The concerns are for the general framework for explaining ways of thinking, and not for practical ways of thinking in particular, so I do not discuss those concerns here.
} 
So perhaps the complaint from Schiffer can be resisted. We can treat the three claims above as the core characterization of PMPs and then assess (i) the extent to which the claims can be defended, and (ii) the extent to which the claims provide a sufficiently informative account of PMPs.

If (8a-c) are informative enough and can be defended in a plausible and fairly clear way, then PMPs deserve more respect than they've been given. I will argue that they cannot be so defended, and that ultimately we are left with an inadequate understanding of what PMPs are supposed to be. Thus we have little reason to believe a theory that appeals to them, and the Intellectualist remains faced with the sufficiency problem.

\section{Assessing the analogy}

We can begin with (8a). The claim is tolerably clear, but not particularly helpful. Knowing that PMPs are connected with certain linguistic constructions doesn't tell us much about what PMPs themselves are like. (For comparison, knowing that numerals refer to numbers doesn't tell us much about what numbers are.) All it tells us is that they're the kind of thing that can play a role in communication. Perhaps attending to the use of the relevant linguistic constructions could be a method for learning more about the nature of PMPs, but that new information would likely be something along the lines of (8b) and (8c), and should be stated as its own component of a characterisation of PMPs. (8a) would not itself capture that new information.

So most of the work in (8)'s explanation of PMPs would be carried out by (8b) and (8c). Take the former first. If true, it would provide exactly the sort of intuitive grounding that we have and need for other modes of presentation. Consider John again, and the difference between (6) and (7). Suppose we want to give an account of the difference between the two states of mind described by those sentences, and we introduce a technical term 'schmode' simply by saying "(6) conveys that John believes a certain proposition p under one schmode, while (7) conveys that he believes $\mathrm{p}$ but under a different schmode". This would clearly be unsatisfactory, for we would be left wondering what 'schmode' really meant and what it would be to entertain a proposition "under a schmode". We would need an explanation of this sort of talk in independently intelligible terms. Now consider a real-life theory that appeals to "indexical modes of presentation". Here in fact our ability to understand the theory depends crucially on our having independently intelligible terms with which to understand the technical vocabulary. We get an intuitive grip on 
what it is to believe a proposition about John under a first-personal mode of presentation by appealing to our pre-theoretical idea that one can think of oneself in different ways. One can think of oneself as oneself, or think of oneself as some person reflected in a mirror. Our understanding of indexical modes of presentation would be much weaker if we didn't explain them in terms of ways of thinking of things.

So if (8b) could be plausibly defended, that would do much to help us get a grip on PMPs. If it cannot, however, then the analogy with indexical modes of presentation is problematic and the demand for an explanation of PMPs must be met by other means.

On reflection, (8b) is implausible. Suppose Hannah and Alice each know that that is a way for them to ride a bicycle (perhaps they are physically fit and are watching a skilled cycling instructor), but only Alice knows how to ride a bicycle herself. Ask yourself what the difference might be between Alice and Hannah, where Hannah doesn't know how to ride a bicycle. What would it take for Hannah to gain the know-how Alice possesses? There is no intuitive appeal to the thought that Hannah simply isn't thinking in the right way about the instructor's way of cycling. But this is exactly what is going on according to the proponent of PMPs, just as the analogous oblivious person with burning pants simply isn't thinking of him or herself in the right way.

Take another of Stanley and Williamson's examples: Joe knows how to wiggle his ears, while Fred doesn't. Joe and Fred are each told by a reliable source that that is a way for them to wiggle their ears, but afterward Fred still doesn't know how to wiggle his ears. Why not? According to the PMP account, Fred just isn't thinking in the right way about the relevant way $w$ of wiggling. It is hard to believe that captures what Fred needs to do. We need an intuitive characterisation of what PMPs are, but there is no intuitive temptation to say,"Fred would know how to wiggle his ears just fine if only he were thinking about $w$ a little differently!"

The contrast with indexical modes of presentation is obvious. John Perry is leaving a trail of sugar throughout the supermarket. He knows that the person making the mess has a cart with a leaking bag of sugar in it, but he doesn't know that he himself has a leaking bag of sugar in his cart. He would know the latter if only he were thinking of the person making the mess as himself. Forgetting that he is back from his winter holiday on the French Riviera, Bob is about to leave his Cambridge home in a t-shirt. He denies "It is cold here", yet he knows well that Cambridge is cold. If only he were thinking about Cambridge in a different way, as "here", he would realize 
that he needed a coat. These natural descriptions of the cases in terms of "ways of thinking" allow us to give content to the technical term 'mode of presentation' and to understand what it is to entertain a thought about a given person or place under an indexical mode of presentation. But there is no analogous natural description of what's going on in the know-how cases, so the intuitive understanding of "ways of thinking" cannot plausibly give content to a technical term 'PMP' which, beforehand, we only know is supposed to label a phenomenon present in those cases.

The observation of this contrast is rather damaging for the PMP account of know-how. The Intellectualist cannot plausibly appeal to the central notion that is used to explain other modes of presentation, and without that notion, there is a genuine threat that PMPs will remain unintelligible.

Before moving on, I want to discuss one possible reply to the objection above. ${ }^{12}$ Perhaps there are some ways of thinking about things that some people are not capable of employing. Perhaps, for instance, if Mary has never heard of Cambridge under the name 'Cambridge' and is utterly unfamiliar with the city, she might not be able to think of the city in the way that we do when we say "Cambridge is F". If we describe the ability to employ a way of thinking in the terminology of "concepts", we can put the point this way: Some people like Mary lack certain concepts of some objects, and when they do, they are unable to think of those objects by employing those concepts. The Intellectualist might try to use this idea to point to a disanalogy between the indexical cases discussed above and the know-how cases. The messy shopper and the Cambridge resident have the indexical concepts they need in order to possess the relevant indexical knowledge. So it's true that in their cases they merely need to think in a different way about themselves or their locations. But the difference between Alice, who does know how to ride a bicycle, and Hannah is not just a difference in how they happen to be thinking of ways of bicycling, but also a difference in what concepts they possess. Similarly, the difference between Joe and Fred is not just a difference in how they are thinking of ways of ear wiggling, but a difference in their conceptual repertoire. So there are differences among the pairs of cases deriving from the fact that indexical concepts are possessed by nearly everyone, and hence we shouldn't expect a complete analogy between indexical knowledge and know-how.

I think the idea above fails to help the Intellectualist. For the force of the original objection is

\footnotetext{
${ }^{12}$ Thanks to Joel Smith for bring this to my attention.
} 
independent of whether the Intellectualist gives a story about why Hannah isn't thinking in the right way of the relevant way of bicycling. What Hannah needs to know according to the Intellectualist is that a certain way $w$ of bicycling is a way for her to ride a bicycle, and she needs to entertain that fact via a special way of thinking about $w$. Now, Hannah does know of $w$ that it is a way for her to ride a bicycle. What she isn't doing, according to the PMP account of know-how, is thinking of $w$ in the right way. That description of her is supposed to be correct regardless of whether or not she is capable of thinking of $w$ in the right way (whether she possesses the right concept of $w$ ). So if the technical notion of a PMP is to be explained in terms of the intuitive notion of ways of thinking, then Hannah's deficiency should be intuitively characterisable as a failure to think in the right way about $w$. But this is not an intuitive characterisation of her situation at all. It doesn't seem right to say, "Alice knows how to ride a bicycle, but Hannah doesn't. Why not? Well, she isn't thinking in the right way about the relevant way of bicycling." For contrast, consider Mary, who is transported to Cambridge and discovers that the city she is in is cold. She has never heard of "Cambridge", however, and is only able to think of the city indexically or on the basis of her immediate surroundings. She lacks the concept required to think of the city as Cambridge. It is fairly natural to explain why Mary doesn't know it's cold in Cambridge by saying that while she is thinking of the city that it is cold, she isn't thinking about the city in the right way.

Furthermore, we should note that talk of concepts doesn't help the proponent of PMPs at all. We can intuitively explain Mary's situation by saying that she doesn't believe that Cambridge is cold because she doesn't even have the concept of Cambridge. In comparison, it is quite unintuitive to say that the reason Alice doesn't know how to ride a bicycle is that she doesn't have a certain concept of a way of bicycling. Given that lack of intuitive plausibility, the theoretical claim that Alice's deficiency is a failure to entertain a proposition about $w$ under a PMP cannot be given intuitive content via ordinary talk about concepts.

So PMPs do not seem explicable in terms of concepts or ways of thinking, and this undermines the attempt to use (8b) to clarify the notion of a PMP. The analogy between PMPs and other modes of presentation is thus missing a major component. However, perhaps if (8c) were spelled out in detail and given a plausible defence, that could be enough to satisfy those who find PMPs obscure. 
We are told very little by Stanley and Williamson or Stanley (2011) about what dispositions come along with believing a proposition under a practical mode of presentation. To highlight part of the block quote from above: "Thinking of a way under a practical mode of presentation undoubtedly entails the possession of certain complex dispositions. It is for this reason that there are intricate connections between knowing-how and dispositional states." Nothing further is said about what these dispositions might be, so we cannot really assess the proposal. However, we can reflect on the dispositional differences between agents who do and agents who don't know how to do things, and try to make a rough proposal on the Intellectualist's behalf.

Return to Joe and Fred. Each knows that that is a way for him to wiggle his ears, but while Joe knows how to wiggle his ears, Fred doesn't. What are the dispositions that would distinguish them? The most obvious suggestion might be that Joe has the disposition to, when desiring to wiggle his ears, wiggle his ears in way $w$, while Fred lacks that disposition. A problem with this proposal is that Intellectualists want to insist that knowing how to do something doesn't require the ability to do it. So whatever disposition one has in virtue of knowing about $w$ under a practical mode of presentation, it must be a disposition that could be possessed by someone who didn't have the ability to wiggle his ears. Now, the disposition to, when desiring to wiggle one's ears, wiggle one's ears in way $w$, either requires the ability to wiggle one's ears or it doesn't. If it does, an Intellectualist can't use that disposition to explain PMPs. If it doesn't, then it is hard to see how it is capturing some essential difference between someone with knowledge under a PMP and someone without. Why couldn't Fred be disposed, when desiring to wiggle his ears, to wiggle his ears in way $w$, given the assumption that it's perfectly possible for him to have that disposition without the ability to wiggle his ears? Without an answer to this question from the Intellectualist, an account of PMPs in terms of the disposition in question seems troublingly unenlightening.

The Intellectualist's desire to separate abilities from the dispositions associated with knowhow leads to further troubling questions. Stanley and Williamson would maintain that just as a current olympic ski jumper knows how to do a triple back flip, so might a former ski jumper who has suffered a debilitating injury. Since knowledge under a PMP doesn't require ability, one doesn't lose know-how merely by losing ability. Consider now a former ski jumper who has aged to become a feeble octogenarian in a wheelchair. Suppose she has the sharpest memory on the planet. Presumably, then, she hasn't forgotten any propositions about ways of skiing. Since her 
loss of ability is independent of what she knows how to do, would Stanley and Williamson say that this elderly woman still knows how to do triple back flips?

Perhaps they would say that. But then it is truly puzzling what dispositions the elderly woman currently has which qualify her as having knowledge about ways of skiing under a PMP. Contrast our elderly woman with another octogenarian, a man who is very well-read when it comes to ski jumping technique, but has never attempted to ski in his life, and never knew how to perform any ski jumping tricks himself. Neither of the two elderly folks are able to do triple back flips. Both know many propositions about ways of performing such tricks. If $(8 \mathrm{c})$ is true, there are some important ski-related dispositional differences between the two. It is not just that there were some ski-related dispositional differences between them, but that they currently possess different skirelated dispositions. Without an explanation of what those differences could be, the account of PMPs remains quite mysterious.

Could Stanley and Williamson say that the elderly former ski jumper no longer knows how to do triple back flips? That claim would seem to me very much against the spirit of Intellectualism, but let us consider it anyway. If Stanley and Williamson said that the old woman didn't know how to perform the trick, it would be hard to see why, on their account, she would have lost her know-how. They say that a youthful and skilled ski jumper with a broken leg still knows how to perform ski tricks despite having lost the ability to do so, so loss of ability must not provide an explanation of the old woman's loss of know-how. What dispositions that are independent of abilities has she lost, and why has she lost those dispositions? We are given no answer to these questions, and it is hard to see what they might be.

Intellectualists might be tempted to say that the old woman's know-how is precluded not by her dispositions but by the truth-value of the proposition that she would need to know. She can't know how to do a triple back flip because for every $w$, it is false that $w$ is a way for her to do a triple back flip. But this would just raise further puzzling questions. Why isn't such-and-such way $w$ a way for the woman to perform the trick? She isn't able do the trick, of course, but that can't answer our question unless know-how requires ability. And saying that the woman is simply too old for $w$ to be a way for her to do a triple back flip is inadequate in lieu of further explanation. For what does being old have to do with whether something is a way for one to $\phi$ The obvious answer is that if one is too old, one isn't able to $\phi I$ don't know what the alternative answer could 
be, and Intellectualists haven't provided one.

Another initially tempting thought might be to double-down on the analogy with indexical modes of presentation. Perhaps to entertain a proposition about $w$ under a PMP, one has to be in a special position vis-a-vis $w$. It is not enough to be able to identify $w$ as that way of doing a triple back flip. Rather, one must be in a position to identify $w$ as this way of doing a back flip (where one demonstrates the relevant way oneself). The old woman cannot put herself in such a position, hence she is unable to entertain the relevant proposition under a PMP. It should be obvious that this suggestion raises more of the same problems. One is able to indexically demonstrate $w$ in the suggested manner only if one is is able to do a triple back flip in way $w$. Hence on this account one knows how to perform the trick only if one is able to perform the trick. This runs counter to the Intellectualist's usual view while also calling into question their claim that a youthful skier with a broken leg might still know how to do a triple back flip. The present strategy is not one the proponent of PMPs should pursue.

To summarise where things stand now: We've seen that pursuing an analogy between PMPs and indexical modes of presentation is the crucial strategy Intellectualists have taken to explain PMPs. The analogy rests on three claims. (8a), while clear enough, contributes relatively little to the characterisation of PMPs, as it only tells us that whatever PMPs are, they are conventionally connected to certain locutions in English. Claim (8b), in contrast, would provide the main tool for understanding what PMPs are supposed to be. However, the claim has little plausibility, compares unfavourably with corresponding claims about indexical modes of presentation, and has been given no substantial defence by Intellectualists to prop it up. That leaves (8c), which if given sufficient support might suffice to make PMPs clear enough to warrant serious consideration. However, such support has not been forthcoming. No account of the relevant dispositions has been given by Intellectualists, the natural suggestion on their behalf fails, and a general worry arises that the dispositions needed to defend PMPs, whatever exactly they might be, cannot be clearly separated from abilities.

All this adds up to the conclusion that an account of know-how in terms of PMPs is not much of an account at all. Without the analogy with indexical modes of presentation, we are left with little if any understanding of what a PMP could be. And thus the Intellectualist is left without much of a response to the sufficiency problem we began with. 


\section{Against a minimal account}

Given the difficulties in fleshing out and defending the analogy between PMPs and indexical modes of presentation, could Intellectualists insist that they needn't provide any detailed account of PMPs? Perhaps they could say so little that they allow PMPs to be something quite different from other modes of presentation. They could allow that when someone knows under a PMP that $w$ is way for her to $\phi$ this is not a matter of her thinking about $w$ or about $\phi$ ng in the right way. Perhaps a PMP should not be understood as a way of thinking something at all. Perhaps they could still claim that knowing a proposition under a PMP involves possessing some dispositions, but reject the request to specify any such dispositions. A PMP, on a minimal account, could be characterised simply as whatever makes the difference between know-how and other knowledgethat.

This unambitious "account" of know-how would obviously leave many unsatisfied. Does it even qualify as an account at all? Perhaps, but I think the force of the sufficiency problem is great enough that such a minimal "account" could not possibly qualify as an adequate response. I'd like to do a bit more to support this thought, emphasising the idea that PMPs must be better explained and justified in order to play any role in a theory of know-how. Let us consider an analogy.

The orthodox view on acquaintance-knowledge, the sort of knowledge we attribute by saying 'John knows Bill', is that it is non-propositional. However, we might entertain the following view: $\mathrm{x}$ knows $\mathrm{y}$ iff $\mathrm{x}$ knows that $\mathrm{y}$ exists, and knows it under an acquaintance-based mode of presentation (AMP). Acquaintance-knowledge, then, would be a kind of knowledge-that.

It might be objected that pairs of sentences like (9) might differ in truth-value:
a. Alice knows that George Bush exists.
b. Alice knows George Bush.

Perhaps Alice has never met George Bush, but has heard of him on the television, from friends, and so on. Then wouldn't (9a) be true but (9b) false? And wouldn't this refute the proposal that acquaintance-knowledge is knowledge-that?

Imagine the following attempt to block the objection: One can only know that George Bush 
exists under an AMP by meeting George Bush in person, talking to him on the phone, or something similar. In this way AMPs resemble certain indexical or demonstrative modes of presentation: to think that that guy is tall, it is not sufficient to think that George Bush is tall, even if that guy is George Bush. Or to think that this guy [on the other end of the phone] is loud, it is not sufficient to think that George Bush is loud, even if this guy is George Bush. Similarly, one needs to be in the right position to grasp a proposition under an AMP, and most people simply have not come to stand in the right relations to Bush to allow them to know that he exists under an AMP. That's why most people don't know George Bush.

It might be further objected that some people know George Bush but do not know that George Bush exists - perhaps John, for instance, met Bush but was introduced to him by a prankster who told him "This is Vladimir Putin”. Having never heard of Bush, John cannot be said to know that George Bush exists, although he knows Bush. Again, AMPs would allow us to block the objection. Anyone who has met Bush knows under some modes of presentation but not others that Bush exists. The fact that they would not assent to 'George Bush exists' is independent of whether they know the proposition the sentence expresses under an AMP.

I suspect that no philosopher would be convinced by the responses on behalf of the above account, and this would be so despite the efforts to portray AMPs as analogous to other modes of presentation. The proposal about acquaintance knowledge is completely unconvincing because we have no intuitive grip on what it is to think that someone exists under an acquaintancebased mode of presentation. The attempted analogy simply lacks the substance necessary to assuage our concern that AMPs are an invention motivated only by the desire to avoid counterexamples. Questions like the following are left unanswered: Why can all and only people who know Bush think that Bush exists under an AMP? Why aren't AMPs simply a way to illicitly rely on the traditional idea about acquaintance-knowledge - that knowing an individual involves having participated in some fairly direct causal interaction with that individual - while eliminating any relevance for the alleged propositional aspect of the knowledge? Why is the proposal an explanation of the intuitions that motivate the two objections above, rather than simply a label for whatever might provide such an explanation?

The point of all this is that if AMPs are an unacceptable defence of the analysis of acquaint- 
ance knowledge as a kind of knowledge-that, then PMPs are an unacceptable defence of the analysis of know-how as a kind of knowledge-that. For we have no better grip on what a PMP is supposed to be. We are told they they are analogous to other modes of presentation, but on inspection, there seems to be no reason to believe that they are.

\section{Stanley's back-up plan}

Stanley has suggested that even if one rejects PMPs / practical ways of thinking, his account of know-how has the resources to explain the appearance that a know-how attribution can be false even given the truth of a knowledge-that attribution which, on Stanley's view, suffices for the know-how. Stanley notes that the following pair of sentences might differ in truth-value, and uses this to illustrate his idea:

(15) a. Hannah knows that that way is a way in which she could ride a bicycle.

b. Hannah knows how to ride a bicycle.

Stanley and Williamson (2001) appeal to practical ways of thinking to explain this contrast. However, the contrast can be explained without appeal to ways of thinking. The difference in meaning between (15a) and (15b) is due to the different modal parameters governing the uses of the modal constructions in these sentences. Though the modals in (15a) and (15b) have the same force - they are kinds of dispositional, or ability modals - they are interpreted via distinct modal parameters. In (15a), the modal parameter is one that takes the world of evaluation, and yields a set of propositions that characterize Hannah's physical state after training for some time with a bicycle. In contrast, the natural modal parameter for the envisaged utterance of (15b) is one that takes the world of evaluation, and yields a set of propositions that characterize Hannah's physical state at the moment. That is why the two utterances express different propositions because the modals in the two sentences are interpreted via distinct modal parameters. (Stanley 2011: 126)

This back-up plan may at first seem to be an improvement over the PMP response to the sufficiency problem, but there are still significant questions about it. The first question is whether Stanley's back-up plan really solves the original problem. In the block quote above, Stanley has set himself too easy a task. For if an overt 'could' is interpreted using different parameters than an infinitival modal is, that means that (15a) is a less accurate report than (3a) of the sort of proposition Hannah is said to know by $(15 b) /(3 b)$. The complement clause of (3a) contains, rather than replaces, the infinitival modal - it says '...for Hannah to ride', instead of 'that Hannah could ride'. So the original (2001) proposal of Stanley and Williamson should, by Stanley's lights, be at least as good if not better than the proposal that (15a) suffices for the truth of (15b). 
So if Stanley's back-up plan is supposed to deal with the sufficiency problem, it should explain why (3a) doesn't suffice for the truth of (3b). But Stanley's proposed explanation of the contrast between $(15 a)$ and $(15 b) /(3 b)$ is that "the difference is due to the distinct modal parameters associated with explicit modals, on the one hand, and the modal associated with infinitival embedded questions, on the other" (Stanley 2011: 125). And the latter modal is just the modal of the infinitival verb phrase. So since (3a) contains that infinitival modal, the fact that it doesn't suffice for the truth of $(15 b) /(3 b)$ can't be explained with the claim that the overt modal 'could' differs in its interpretation from the covert infinitival modal. The modal in (3a) just is the modal in $(15 b) /(3 b)$.

Perhaps Stanley's claim should be not that the modals themselves are distinct, thus leading to different parameters being used in their interpretations, but instead that the modals are interpreted using different parameters for independent reasons. We would need a clear story about why this would be so, but it is not obvious how such a story would go. There are no longer two different modal constructions ('could' and 'to ride'), but a single modal construction twice: 'to ride'. So it's hard to know why there should be "different modal parameters governing the uses of the modal constructions in these sentences". Stanley gives us no explanation.

The only explanation I can offer on Stanley's behalf is that the modal constructions occur in differing linguistic contexts ('for Hannah to ride' vs. 'how to ride'), and those contexts would convey to the listener that different particular modal parameters were relevant. Stanley would need to provide details of how those linguistic contexts would do that, but even if he could, that explanation might not apply to the following pair:

(10) a. Hannah knows that that is how to ride a bicycle.

b. Hannah knows how to ride a bicycle.

In the same context we've imagined for (3a) and Stanley's (15a), we again have an intuitive difference in truth-value. Hannah might not know how to ride a bicycle even if she knows that that is how to ride a bicycle. But now not only is it true that we have the same modal construction occurring in each sentence, but we have the same modal construction appearing within the same larger construction, 'how to ride a bicycle'. There are some differences remaining between the 
sentences, but it is totally unclear why they would be of any relevance to the parameters used in the interpretation of the modal. If Stanley's back-up plan is to be successful, he must give an account of why they would be.

A further significant question, although one which I won't discuss at length here, is this: Given that Stanley's more recent position is that the infinitival modal is a kind of "dispositional, or ability modal", how much of a concession is this to the Anti-Intellectualist? I take it that it would be fairly concessive to claim that know-how is knowledge of ability, since Stanley and Williamson strongly emphasised that know-how did not entail ability. In his recent work Stanley views himself as resisting the concession, but it is not clear to me that that is what he is doing. He shows that some occurrences of the infinitival modal are interpreted with different parameters than some occurrences of 'able', but that shows little, since some occurrences of 'able' are interpreted with different parameters than other occurrences of 'able'. The Anti-Intellectualist says that knowing how to bicycle entails being able to bicycle, and to refute this Stanley would need to show that that claim is not true given the parameters appropriate to the relevant use of 'able'.

Adopting the claim that know-how entails ability would solve several problems for a theorist who is satisfied with holding on to the claim that know-how is a kind of knowledge-that. First, the sufficiency problem would be avoided. For example, ${ }^{13}$ suppose John knows how to swim iff John knows that he is able to swim in way $w$. If John knows that he is able to swim in way $w$, then he knows that he is able to swim, and hence it is true that he is able to swim. And plausibly, if John doesn't know how to swim, then he isn't able to swim. So if John is able to swim, then he knows how to swim. Hence no sufficiency problem. Second, an account of know-how on which it entails ability has no need to use ways of thinking to characterise the difference between John knowing that $w$ is a way for him to swim and John knowing how to swim. So any problems for that latter characterisation are irrelevant. Third, the account avoids the problem discussed above for using dispositions to characterise the difference between someone who knows how to swim and someone who doesn't, but still knows various facts about swimming. The problem was that we couldn't identify dispositions that were sufficient to explain the difference without turning those dispositions into ones that sufficed for ability. On the present concessive view, we could

\footnotetext{
${ }^{13}$ See (Glick 2012) for discussion.
} 
simply accept that the relevant dispositions do suffice for abilities, since they are abilities.

Of course, to defend a view like the one above, we should have independent support for the claim that know-how entails ability, an account of the notion of ability with which this claim should be construed, and an explanation of how to deal with alleged counterexamples to knowhow requiring ability. ${ }^{14}$ I have attempted to provide some of these elements previously (Glick 2012), and cannot rehearse all the relevant considerations here. But even without having explored a positive proposal here for responding to the sufficiency problem, we've seen that PMPs are not an adequately clear and plausible tool for dealing with that problem. The Intellectualist's central strategy for explaining PMPs has been to claim that PMPs are analogous to indexical modes of presentation, but the analogy falls apart upon examination. Unlike indexical knowledge, the special characteristics of know-how do not seem naturally captured in terms of "ways of thinking". And this leaves the technical notion of a PMP lacking in intuitive content. Further, unlike with indexical modes of presentation, the alleged dispositions that distinguish subjects who possess knowledge under a PMP are difficult to get a grip on. No proposal as to what the dispositions might be has been offered in the literature, and attempting to provide such a proposal immediately runs afoul of the usual Intellectualist claim that know-how does not require ability.

\section{References}

Azar, Beth. 1998. Why can't this man feel whether or not he's standing up? APA Monitor 29 (6).

Ball, Derek. 2009. There are no phenomenal concepts. Mind 118 (472):935-962.

Bengson, John, and Marc A. Moffett. 2012a. Knowing how. Oxford: Oxford University Press.

Bengson, John, and Marc A. Moffett. 2012b. Non-propositional intellectualism. In Bengson and Moffett (2012a).

Brown, Jessica and Mikkel Gerken. 2012. Knowedge Ascriptions. Oxford: Oxford University Press.

Fantl, Jeremy. 2008. Knowing-how and knowing-that. Philosophy Compass 3:451-470.

Ginet, Carl. 1975. Knowledge, perception, and memory. Boston: Reidel.

Glick, Ephraim. 2012. Abilities and know-how attributions. In Brown and Gerken (2012).

\footnotetext{
${ }^{14}$ Perhaps help with the problem can be found in the literature on dispositions, abilities, and freewill. See, for instance (Whittle 2010), which points to various notions of ability. We might consider some of these as candidates for the Anti-Intellectualist's intended notion.
} 
Glick, Ephraim. 2011. Two methodologies for evaluating Intellectualism. Philosophy and Phenomenological Research 83:398-434.

Koethe, John. 2002. Stanley and Williamson on knowing how. Journal of Philosophy 99:325328.

Noë, Alva. 2005. Against Intellectualism. Analysis 65:278-290.

Perry, John. 2000. The problem of the essential indexical and other essays. Stanford: CSLI, expanded edition edition.

Schiffer, Stephen. 2002. Amazing knowledge. Journal of Philosophy 99:200-202.

Stalnaker, Robert. 2012. Intellectualism and the objects of knowledge. Philosophy and Phenomenological Research 85 (3):754-61.

Stanley, Jason. 2012. Replies to Dickie, Schroeder, and Stalnaker. Philosophy and Phenomenological Research 85 (3):762-78.

Stanley, Jason. 2011. Know how. Oxford University Press.

Stanley, Jason, and Timothy Williamson. 2001. Knowing how. Journal of Philosophy 97:411-44.

Whittle, Ann. 2010. Dispositional abilities. Philosophers' Imprint 10:1-23. 